Regular Issue

\title{
Artificial Intelligence applied to project success: a literature review
}

\author{
Daniel Magaña Martínez, Juan Carlos Fernández-Rodríguez \\ Universidad Antonio de Nebrija, Madrid, Spain
}

\begin{abstract}
Project control and monitoring tools are based on expert judgement and parametric tools. Projects are the means by which companies implement their strategies. However project success rates are still very low. This is a worrying situation that has a great economic impact so alternative tools for project success prediction must be proposed in order to estimate project success or identify critical factors of success. Some of these tools are based on Artificial Intelligence. In this paper we will carry out a literature review of those papers that use Artificial Intelligence as a tool for project success estimation or critical success factor identification.
\end{abstract}

Keywords - Project Management, Artificial Intelligence, Decision Support Systems, Project Success, Critical Success Factors.

\section{INTRODUCTION}

$\mathrm{P}$ ROJECT management is the main tool for implementing a company's goals so understanding its key issues is really absolutely vital for Project success [1].

The main challenge of project Management, whether in the times of the Romans, the Renaissance or the present, is to accomplish Project objectives as specified in the main bodies of knowledge PMBOK[2], PRINCE2[3] e ISO21500[4].

Nevertheless, and in spite of the considerable length of time that Project Management has been in existence, and the improvements of the last few years, there are a lot of projects that are still being classified as not successful, in terms of the way they have been managed or because of their results [5], [6].

Some determining factors have been identified in Project Management literature:

1. Projects have always been associated with complexity [7], but they are getting more complex in general, independently of the industry [8], [9].

2. Stakeholders play an important role in project development, it is not just the realm of the project manager and their team. [10]-[14].

3. Projects have always been surrounded by uncertainty and continuous changes that make it really difficult to plan, and accomplish, schedules, resources and budgets [14]-[18].

As identified in the different bodies of knowledge, PMBok[2], Prince2[3] e ISO21500[4] most of the processes are based on expert judgement or on other parametric analytic tools. The fact that expert judgement is one of the most important tools in project management has some limitations:

1. Projects are normally developed in a restricted resource environment so the more complex is a project is, the more accuracy that is needed, and the more difficult it is to apply this expert judgement.
2. Expert judgement is applied by people, by experts so it can lead to bias [19].

On the other hand the bodies of knowledge identify other processes related to learned lessons of the project as part of the methodology for obtaining better results, learning from past experience [2]-[4] and managing all that knowledge in an effective way [20]. However reality shows that, in general, lessons learned are treated in a very superficial way, they are not well documented and they are not communicated so others can take advantage of them in future projects [21]-[23]. This is probably because lessons learned are perceived in a negative or punitive way in many companies [22].

Summarizing, it seems that traditional project tools are not working properly when trying to predict project success. Accordingly new project management tools are emerging in order to improve project success or project success estimation.

The goal of this paper is to review these new proposals that use Artificial Intelligence to improve project success or that can simply predict it. If we were able to predict the future, we would be able to prepare for it. Originally future prediction in project management has been done from the point of view of expert judgement, based on the opinion of those who are analysing the project, the experts. There are studies that try to make a model of this expert knowledge so technology could mitigate the identified risks [24], [25] and consequentially be applied to project management.

\section{LITERATURE REVIEW METHODOLOGY}

Different references have been found in scientific literature associated with the use of alternative tools to those used in the main bodies of knowledge, some of which are based on Artificial Intelligence. These alternative tools are applied to various project management areas:

1. Estimation of project success

2. Identification of critical success factors

3. Relatedness to project budget

4. Connection to project schedule

5. Project planning

6. Relatedness to risk identification

In this paper we will focus only on those using Artificial Intelligence algorithms to try to conduct a project success estimation o try to identify critical success factors of a project.

In order to carry out this literature review we have done an unstructured initial search just to identify different approaches and goals in the field of artificial intelligence applied to project management. The main objective is to identify the algorithms that are being used for this purpose. The keywords used for this search have been: "project management", "artificial intelligence", "project success", "project success prediction", and "critical success factors". 
Subsequently new structured searches have been made for each of the algorithms in order to find more references to complete in this way the bibliography to be analysed. Repeated searches have been made combining these keywords: "critical success factors", "Project success" with every algorithm identified in unstructured previous searches.

Both searches, unstructured and structured, have been limited to scientific papers, books or book chapters, excluding non-scientific articles. The researche has been done using Bucea searching tool at Universidad Complutense de Madrid, Spain.

The result of these searches is 16 references where Artificial Intelligence has been applied to project success estimation or critical success factor identification. Identified references start in 1997 and finish in 2014.

Based on these results, we will perform a structured analysis in order to identify how artificial intelligence algorithms are applied, detect the authors' objectives and list their limitations. Finally we will summarize the authors' conclusions.

Therefore the following questions arise after this literature review process:

1. What are the authors' goals when applying artificial intelligence to project success?

2. What artificial intelligence algorithms have been applied?

3. What limitations are identified when applying those algorithms?

In the next section we will perform a project success concept definition based on existing principle perspectives on scientific literature.

\section{PRoJeCt SUCCESS}

One of the main worries of project management directors is knowing, with some anticipation, if the project they are managing is going to be successful or not. This worry is not a guessing game. It is supported by control and monitoring tools defined in project management frameworks and the bodies of knowledge [2]-[4].

It is not the goal of this paper to review the vast existing literature associated with project success. We would like to conceptualize the project success concept based on the main existing research lines so it can help the reader to understand how artificial intelligence can help in this area.

A project has been, traditionally, categorized as successful if it accomplished the Triple Constraint: scope, budget and schedule [26]. Traditional statistics or parametrical tools were enough for this purpose. However these tools leave aside other qualitative aspects of project management, for example the stakeholders' point of view [27], [28].

Initial studies in this field conclude that we should distinguish project success concepts, focusing on managerial processes of project management on the one hand, and the traditional Triple Constraint of scope, schedule, budget and quality on the other hand where product success criteria is more important from the product point of view. In this regard a project could have been perfectly managed from the project team's point of view, but the product is not in accordance with the stakeholders' expectations [7], [11], [29].

Some authors have concluded that a correct definition of project success or project failure has not been made and this is one of the main reasons why projects are still being considered as failures [27], [30], [31].

There is a variety of studies proposing new key indicators to create a new framework in order to measure project success based on five dimensions: project performance, project impact on the customer, project impact on the business and its preparation for the future [11], [27], [30], [32].

There is another field of research in literature of those who try to identify the project's critical success factors [26], [33].

\section{ARTIFICIAL INTELLIGENCE ALGORITHM'S APPLIED TO PROJECT SUCCESS}

During this literature review, the following algorithms based on artificial intelligence, and applied to project success have been found.

\section{A. Neural Networks}

Neural Networks attempt to simulate, to a degree, human way of thinking, and are used, nowadays, for multiple purposes, from credit approval, fraud detection, surveillance systems and other kinds of prediction purposes.

One of the main parts of neural networks consists of learner training so neural network adjust to data patterns and give better results. This training is done comparing neural network results with real and known data and is repeated so it adjusts until results of a very low error rate are achieved.

Neural networks, because of their characteristics, are more accurate than linear models [34], based on regression models, which have been frequently used in project management [35].

\section{B. Fuzzy Cognitive Maps}

Fuzzy Cognitive Maps are fuzzy graphical structures that allow the representation of causal reasoning. This graphical representation is made of nodes where the most relevant nodes are specifically identified for a decision-making system. Fuzzy cognitive maps have their origin in a fuse of fuzzy logic and neural networks [36].

\section{Genetic Algorithms}

Genetic Algorithms try to simulate the evolutionary natural process and were originally proposed by Holland [37].

They are easy to apply so they can be fused with other heuristic methods creating ad-hoc solutions. However it is difficult to apply them to large, complex, difficult-to-solve problems [38].

\section{Bayesian Model}

Bayesian networks are described as a representation of a joint probability distribution. It is one of the most common methods for data classification in different categories [39].

The Bayesian model allow us to answer questions such as what is the probability of $\mathrm{X}$ being in state $x_{1}$ if $\mathrm{Y}=y_{1}$ and $\mathrm{Z}=z_{1}$. In other words, links the probability of A given $\mathrm{B}$ with the probability of $\mathrm{B}$ given $\mathrm{A}$.

\section{E. Evolutionary Fuzzy Neural Inference Model - EFNIM}

EFNIM fuses genetic algorithms, fuzzy logic, and neural networks and has been traditionally used for civil engineering problem solving. The combination of these three algorithms makes the strengths of one cover the weaknesses of the other. So genetic algorithms are used for optimization purposes, fuzzy logic deals with uncertainty and neural networks for mapping inputs and outputs.[38]

\section{F. Evolutionary Fuzzy Hybrid Neural Network - EFHNN}

The model EFHNN includes four algorithms of artificial intelligence:

1. Neural Network

2. High Order Neural Network

3. Fuzzy Logic

4. Genetic Algorithm 
Neural Networks and High Order Neural Networks, named together as Hybrid Neural Network (HNN), manage the inference engine while Fuzzy Logic deals with the fuzzy layer. Genetic algorithms optimize the final model.

The difference with EFNIM is that this model is able to manage problems more deeply thanks to the large number of HNN models. [40].

\section{G. Support Vector Machine}

This is a new way of learning, which is more powerful than traditional learning tools. It is able to solve data categorization problems and regression problems as well.

Just as neural networks do, SVM requires training and testing with a training dataset. SVM's characteristics allow it to deal better with unknown data and, generally speaking, they present some advantages over neural networks. They are being applied successfully to cost estimation in the construction industry.

\section{H. Fast Messy Genetic Algorithm}

The Fast Messy Genetic Algorithm can identify optimal solutions in an efficient way to problems with a large number of permutations. It is known because of its flexibility and because it can be fused with other methodologies to get better results [41].

The difference between it and other genetic algorithms is based on the possibility of modifying building blocks to better identify partial solutions so as to focus on a global solution faster.

\section{K-Means Clustering}

$\mathrm{K}-\mathrm{Means}$ is an easy approach for creating data cluster from random data. It is commonly used for image pattern detection as well as for many other applications. Its main problem is that it cannot ensure an optimal convergence, but is widely used due to its simplicity.

\section{$J$. Bootstrap aggregating neural networks}

Bootstrap aggregating neural networks are a combination of multiple artificial neural network classifiers. They use more than one classifier based on ANNs so the final decision is taken from each classifier by a voting system [42].

\section{$K$. Adaptive boosting neural networks}

The main difference with Bootstrap aggregating neural networks is that adaptive boosting neural networks use weights that are readjusted on every iteration giving less importance to those solutions that have not been classified correctly. As a result, classifiers focus on more complex samples obtaining a faster solution each time [42].

\section{LITERATURE REVIEW}

As a field of research, the application of artificial intelligence algorithms to the prediction of project success brought up a wide selection of authors' objectives. For a better comprehension we will divide them into two groups, those that try to predict project success and those that try to identify critical success factors.

\section{A. Determining Critical Success Factors}

Within these groups we find those that apply artificial intelligence algorithms to critical success factors identification for measuring project success [36], [39], [43]-[46].

Multiple studies affirm that project success is not only a matter of complying with the already known Triple Constraint, but also depends on the perception of success by the stakeholder, and that what could be satisfactory for one could be unsatisfactory for the other. Because of this, it is essential to define project success criteria [47]. Furthermore, critical success factors may vary during the project life cycle so it is important to identify them throughout the project.

From this starting point, these algorithms have been identified in literature reviews in order to detect critical success factors of projects (CSF's):
1. Neural Networks
2. Fuzzy Cognitive Maps
3. Genetic Algorithms
4. The Bayesian Model

The first paper is focussed on the construction industry, and its objective is to detect CSFs using neural networks. It identifies eight key factors for project management success [43]:

1. The number of organization levels between the project manager and project staff.

2. How detailed the project design is before the construction phase.

3. The number of control meetings during the construction phase.

4. The number of times that the budget has been updated.

5. The setting up of a constructability system.

6. Team rotation.

7. The amount of money spent on project management.

8. The technical expertise of the project manager.

The author uses data collected for his thesis [48] and analyses them with neural networks in order to get a mapping between managerial elements of project management and project management performance. The final model could be applied as a prediction tool for new project management strategies in the early stages of a project. In conclusion, this model could be also used for project budget performance prediction.

Focusing on defence projects, we find a comparative between neural networks and regression analysis tools for identifying managerial project management criteria oriented to project success in high technology defence projects. In this comparative some factors are identified as less important by regression models while they become more important with the use of neural network algorithms. Neural network algorithms are significantly more accurate when working with unknown data. The author performs his study based on data collected from 89 defence projects developed in Israel between the 80s and 90s [44].

Centred on the IT sector, classified by the authors as different from other sectors due to its complexity and high possibilities of failure, a model for mapping the project's success and CSF's perception, and the link between them is proposed. To perform this mapping, it uses Fuzzy Cognitive Maps (FCMs). The authors defend that the success concept in IT projects is a complex concept, not structured, and so FCM is more appropriate for dealing with this kind of ambiguity. FCM is better suited to IT projects. The authors validate their model with a real project case. The model has a weakness related to the SRMS matrix that shows some wrong data so it needs reviewing by an expert to analyse and correct results [45].

The same authors perform a benchmarking between three emerging methodologies oriented to CSF identification. The three benchmarked methodologies are Critical Success Chains (CSC) [49], Analytic Hierarchy Process (AHP) [50]one central issue is the study of critical success factors (CSF and Fuzzy Cognitive Maps (FCM) [45], all focused on IT projects. The authors conclude by listing advantages, disadvantages and limitations of each of them. As Fuzzy Cognitive Maps is the only one related to Artificial Intelligence, we should 
remark that it is the one most similar to human perception, but even so it requires an expert for its interpretation, and this situation introduces subjectivity into the model as commented in their previous paper.

Again related to IT projects, more specifically software development, the authors make a proposal of a model for identifying the CSF that could impact on project outcome to a greater extent. The objective is to provide a tool for the project manager that allows him to control those identified risks that threaten the project outcome. The authors focus on resources assignation to solve these factors. The authors attempt to identify the most important risks, and suggest the most efficient resource investment based on those risks. They define efficiency as the rate between success probability and cost. This efficiency definition is used as an aptitude function for genetic algorithms. To perform this research, the authors use a dataset of previous software development projects developed both in-house and outsourced within the Chilean industry. The authors applied genetic algorithms to obtain this optimization of resources, and the prediction of success. The model also suggests a cost effective investment proposal [46] .

Finally, and using an expert system based on a Bayesian model and centred on IT projects, again we find a paper whose objective is to know in advance the impact that decisions have on the project's outcome. The authors have a double aim. Firstly to create an expert model, based on a Bayesian model, which allows the project manager to analyse the impact of a decision on project outcome. They use success criteria definitions found in literature. Secondly, to make a recompilation of IT project-related knowledge. The main conclusions of this study are related to the importance of stakeholder engagement, support of senior management, goals and objectives definition and their association with project success [39].

\section{B. Determining project success}

Furthermore we find papers that try to forecast project success for the duration of the project life cycle in its early stage, or at any other time point of the project [38], [40], [42], [51]-[54]the project management, in which the final status of project is estimated, must be incorporated.In this paper, we consider estimation of the final status(that is, successful or unsuccessfulDuring the literature review, these algorithms applied to project success prediction have been found:
1. Bayesian Model
2. Evolutionary Fuzzy Neural Inference Model - EFNIM
3. Neural Networks
4. Support Vector Machine
5. Fast Messy Genetic Algorithm
6. K-Means Clustering
7. Bootstrap aggregating neural networks
8. Adaptive boosting neural networks

Artificial Intelligence application for project success predicting is relatively recent, since the first reference is from 2006. This model estimates project final state applying a Bayesian classifier to different metrics collected from a project. The aim of this research is to make this estimation in the early stages of the project. Metrics selection can be performed by experts or using statistical methods, which are more accurate. The research is focused on IT software development and the authors consider a project as successful if it has been developed on schedule, on budget and to a satisfactory quality. The study is supported by data collected from 28 software development in-house projects. Results show that an accurate success prediction can be made, but having the right metrics is a key issue for getting accurate results [51].

The next paper, focused on the construction industry, suggests a model for a dynamic project success estimation. The model, named
EPSPM, fuses several artificial intelligence algorithms: genetic algorithms (GAs) for optimization, fuzzy logic (FL) for reasoning and neural networks (NN) for mapping inputs and outputs. EPSPM is integrated with the Continuous Assessment of Project Success tool [55], which allows us to create a real time decision-making system. The authors define project success in the construction industry as that which conforms to the budget, the schedule, the performance and the project safety, in addition to other subjective criteria. The project outcome could be influenced by many different factors along the project cycle, so it is interesting to rely on a tool that allows us to predict project success in any given project. This, somehow, could be done by human beings based on experience, as has traditionally been done. Accordingly, artificial intelligence trying to simulate the human brain could be very helpful. The EPSPM model allows estimating project success at any time selecting critical success factors in every project life cycle phase. It is also supported by a historical project database that allows pattern identification for analysis. Research results show that the suggested model is a valid tool for project managers which allows them to make project success estimations in real time [52]which requires a continuous monitoring and control procedure. To dynamically predict project success, this research proposes an evolutionary project success prediction model (EPSPM .

Centred on the sectors of construction and industry, and with a slightly different approach from the rest of the papers, we find a study based on the importance of pre-planning before the project begins.

Project schedule and budget are identified as main success key elements. A wrong project scope definition may lead to a hike in a project's budget and schedule. The aim of this paper is to create a model that permits us to predict this cost and Schedule increments based on data collected from 62 industrial projects and 78 construction projects. Their intention is to relate the planning prior to the project with its success, with the cost and schedule as principle indicators. The authors use a tool called The Project Definition Rating Index (PDRI) to evaluate how well the project scope is defined before the project begins. Research has been performed from data collected with this tool. The authors used two models, the first based on a statistical approach, and the second on neural networks. Even though both models confirm the link between pre-planning and Project success, neural networks are more accurate. In addition, the model based on neural networks can predict costs and time increments based on PDRI's project punctuation. [53].

Once more focusing on the construction industry, we find a paper suggesting a hybrid model fusing several artificial intelligence algorithms. It uses an inference model named Evolutionary Support Vector Machine Inference Model (ESIM) for dynamically predicting project success. The model fuses Support Vector Machine (SVM) for learning and Fast Messy Genetic Algorithm (fmGA) for optimization. This hybrid model is integrated with CAPP, as previous papers have done, for identifying critical success factors and for doing a real time project success prediction. Research results are that ESIM can predict project success with remarkable accuracy. The model was trained and tested with datasets from 46 CAPP projects. To obtain better results, the authors used $K$-means to select projects with similar characteristics [54]while fmGA deals primarily with optimization. Furthermore, the model integrates the process of Continuous Assessment of Project Performance (CAPP.

With exactly the same aim of predicting Project success dynamically, there is another paper that also fuses several artificial intelligence tools. The algorithms fused are $K$-means clustering, genetic algorithms (GA), fuzzy logic (FL) and neural networks (NN). Once again CAPP is used for dynamically identifying the project's critical success factors. As above, $K$-means is used in order to get similar datasets. FL is used for dealing with uncertainty, $\mathrm{NN}$ for datamining and GA for 
optimization. The result of this research is a new developed model named Evolutionary Fuzzy Neural Inference Model (EFNIM), which is able to accurately estimate project success [38].

In the same line of previous papers, not in vain shares one of the authors, we find a paper that fuses more artificial intelligence tools to create an evolutionary model. This time the selected tools are neural networks fused with high order neural networks fused with fuzzy logic and genetics algorithms creating a model named Evolutionary Fuzzy Hybrid Neural Network (EFHNN), integrated again with CAPP for dynamically identifying critical success factors. The main difference with EFNIM is the combined use of neural networks and high order neural networks, which allow greater flexibility and let us see how mapped inputs and outputs of the model really are [40].

The most recent paper is based on project planning in the early stages to predict project success in costs and schedule terms. It relies on PDRI for determining a rate of project definition before the project starts. To make this prediction, it uses two models based on neural networks and Support Vector Machine. As cost and schedule indicators have important differences, the authors have developed two different models, one for each indicator. In the case of costs, the authors' conclusion is that the best is $S V M$ with an accuracy of $92 \%$, followed by Adaptive Boosting and finally Bootstrap Aggregating. In the case of the schedule, results are slightly worse. With a rate of $80 \%$ corresponding to Adaptive Boosting followed by SVMs and Bootstrap Aggregating. As demonstrated in other papers the project's pre-planning is a critical success factor. [53].

\section{CONCLUSIONS}

The possibility of project success prediction or identifying critical success factors in advance is a field of research where researchers have been working intensively for project management purposes.

Initial approaches have been based on statistical models that had not been able to answer to project Management needs. In artificial intelligence, researchers have found algorithms and tools that deal better with project uncertainty and complex environments where projects are normally developed. Several algorithms deal with specific goals.

Critical success factors identification:
1. Neural Networks
2. Fuzzy Cognitive Maps
3. Genetic Algorithms
4. Bayesian Model

Project success prediction:

1. Bayesian Model

2. Evolutionary Fuzzy Neural Inference Model - EFNIM

3. Neural Networks

4. Support Vector Machine

5. Fast Messy Genetic Algorithm

6. K-Means Clustering

7. Bootstrap aggregating neural networks

8. Adaptive boosting neural networks

The main conclusions obtained from the reviewed papers are that artificial intelligence tools are more accurate than traditional tools, but are still complementary to traditional tools. Artificial Intelligence tools are really helpful for the project manager to control and monitor the project.
However some of the reviewed models have weaknesses and limitations that indicate project managers should still use expert judgement and compare artificial intelligence results with traditional tools before making a decision, so they can adjust them if necessary.

Trending is fusing different artificial intelligence tools so they can take advantage of the strengths of a tool and cover the weaknesses of the rest. Best results are obtained when fusing artificial intelligence tools with specific project tools like CAPP, which permits real-time analysis, and PDRI, which allows the rating of how a project has been defined in its very early stages, before a project begins.

\section{REFERENCES}

[1] J. K. Pinto and J. E. Prescott, "Variations In Critical Success Factors Over The Stages In T," J. Manage., vol. 14, no. 1, 1988.

[2] Project Management Institute, Project Management Body of Knowledge (PMBOK), 5th editio. Project Management Institute, Inc., 2013.

[3] A. Murray, N. Bennett, and C. Bentley, Managing successful projects with PRINCE2, 2009 edition manual. London: The Stationery Office, 2009.

[4] "Directrices para la gestión de proyectos," UNE-ISO 21500. AENOR, 2012.

[5] The Standish Group, "CHAOS MANIFESTO 2013." The standish Group, 2013.

[6] R. L. Glass, "IT Failure Rates - 70\% or 10-15\%?," IEEE Softw., vol. 22, no. 3, pp. 112, 110-111, May 2005.

[7] D. Baccarini, "The logical framework method for defining project success," Proj. Manag. J., vol. 30, no. 4, pp. 25-32, 1999.

[8] H. Kerzner, "The Future of Project Management By The Importance of Recognizing Change." pp. 1-127, 2013.

[9] M. Saynisch, "Beyond frontiers of traditional project management: An approach to evolutionary, self-organizational principles and the complexity theory-results of the research program," Proj. Manag. J., vol. 41, no. 2, pp. 21-37, Apr. 2010.

[10] K. Davis, "ScienceDirect Different stakeholder groups and their perceptions of project success," JPMA, vol. 32, no. 2, pp. 189-201, 2014.

[11] A. J. Shenhar, O. Levy, and D. Dvir, "Mapping the Dimensions of Project Success.," Proj. Manag. J., vol. 28, no. 2, pp. 5-13, 1997.

[12] G. Indelicato, "Project Management Metrics, KPIs, and Dashboards: A Guide to Measuring and Monitoring Project Performance," Proj. Manag. $J$., vol. 43, no. 2, pp. 102-102, Apr. 2012.

[13] X. Wang and J. Huang, "The relationships between key stakeholders' project performance and project success: Perceptions of Chinese construction supervising engineers," Int. J. Proj. Manag., vol. 24, pp. 253-260, 2006.

[14] F. N. D. Piraquive, R. G. Crespo, and V. H. M. García, "Analysis and Improvement of the Management of IT Projects," IEEE Lat. Am. Trans., vol. 13, no. 7, pp. 2366-2371, 2015.

[15] L. A. Ika, "Project success as a topic in project management journals," Proj. Manag. J., vol. 40, no. 4, pp. 6-19, Dec. 2009.

[16] J. G. Geraldi, L. Lee-Kelley, and E. Kutsch, "The Titanic sunk, so what? Project manager response to unexpected events," ... J. Proj. Manag., vol. 28, no. 6, pp. 547-558, 2010.

[17] B. Sauser, R. Reilly, and A. Shenhar, "Why projects fail? How contingency theory can provide new insights-A comparative analysis of NASA's Mars Climate Orbiter loss," Int. J. Proj. ..., vol. 27, no. 7, pp. 665-679, Oct. 2009.

[18] J. G. Geraldi and G. Adlbrecht, "On faith, fact and interaction in projects," Proj. Manag. J., vol. 38, no. 1, pp. 32-44, 2007.

[19] B. Shore, "Systematic biases and culture in project failures," Proj. Manag. J., vol. 39, no. 4, pp. 5-16, Nov. 2008.

[20] R. G. C. Flor Nancy Díaz Piraquive, Víctor Hugo Medina García, "Knowledge Management Model for Project Management," in Knowledge Management in Organizations, Springer International Publishing, 2015, pp. 235-247.

[21] K. Jugdev, F. Business, S. Winston, C. Avenue, and S. Albert, "Learning from Lessons Learned : Project Management Research Program," Am. J. Econ. Bus. Adm. 4 13-22, 2012 ISSN 1945-5488, vol. 4, no. 1, pp. 13-22, 2012. 
[22] J. Julian, "How project management office leaders facilitate cross-project learning and continuous improvement," Proj. Manag. J., vol. 39, no. 3, pp. 43-58, Sep. 2008.

[23] F. F. T. Anbari, E. G. Carayannis, and R. J. Voetsch, "Post-project reviews as a key project management competence,” Technovation, vol. 28, no. 10, pp. 633-643, 2008.

[24] J. M. Castillo, C. Cortes, J. Gonzalez, and A. Benito, "Prospecting The Future with AI," Int. J. Artif. Intell. Interact. Multimed., vol. 1, no. 2, pp. $1-53$.

[25] J. M. Castillo, “A crystal ball made of agents," Int. J. Interact. Multimed. Artif. Intell., vol. 1, no. 3, p. 13, 2010.

[26] J. K. Pinto and D. P. Slevin, "Critical success factors across the project life cycle,” Proj. Manag. J., vol. 19, pp. 67-75, 1988.

[27] T. Cooke-Davies, "The 'real' success factors on projects," Int. J. Proj. Manag., vol. 20, no. 3, pp. 185-190, Apr. 2002.

[28] J. K. Pinto and S. J. Mantel, "The causes of project failure," IEEE Trans. Eng. Manag., vol. 37, no. 4, pp. 269-276, 1990.

[29] A. de Wit, "Measurement of project success," Int. J. Proj. Manag., vol. 6, no. 3, pp. 164-170, Aug. 1988 .

[30] I. Hyvari, "Success of projects in different organizational conditions," Proj. Manag. J., vol. 37, no. 4, pp. 31-42, 2006.

[31] A. J. Shenhar, D. Dvir, O. Levy, and A. C. Maltz, "Project Success: A Multidimensional Strategic Concept," Long Range Plann., vol. 34, no. 6, pp. 699-725, Dec. 2001.

[32] L. a. Kappelman, L. Zhang, and R. McKeeman, "Early Warning Signs of it Project Failure: The Dominant Dozen," Inf. Syst. Manag., vol. 23, no. 4, pp. 31-36, Sep. 2006.

[33] F. Hartman and R. Ashrafi, "Project management in the information systems and information technologies industries," Proj. Manag. J., 2002.

[34] K. L. Priddy and P. E. Keller, Artificial Neural Networks. 1000 20th Street, Bellingham, WA 98227-0010 USA: SPIE, 2005.

[35] J. K. Pinto and D. P. Slevin, "Critical factors in successful project implementation," IEEE Trans. Eng. Manag., vol. EM-34, no. 1, pp. 22-27, 1987.

[36] L. Rodriguez-Repiso, R. Setchi, and J. L. Salmeron, "Modelling IT projects success: Emerging methodologies reviewed," Technovation, vol. 27, no. 10, pp. 582-594, Oct. 2007.

[37] J. H. Holland, Adaptation in Natural and Artificial Systems, vol. Ann Arbor. 1975.

[38] M.-Y. Cheng, L. Li-Cuan, H.-C. Tsai, and C. Pi-Hung, "Artificial Intelligence Approaches to Dynamic Project Success Assessment Taxonomic," Life Sci. J., 2012.

[39] L. Gingnell, U. Franke, R. Lagerström, E. Ericsson, and J. Lilliesköld, "Quantifying Success Factors for IT Projects-An Expert-Based Bayesian Model," Inf. Syst. Manag., vol. 31, no. 1, pp. 21-36, 2014.

[40] M.-Y. Cheng, H.-C. Tsai, and E. Sudjono, "Evolutionary fuzzy hybrid neural network for dynamic project success assessment in construction industry," Autom. Constr., vol. 21, pp. 46-51, Jan. 2012.

[41] D. Goldberg, B. Korb, and K. Deb, "Messy genetic algorithms: Motivation, analysis, and first results," Complex Syst., vol. 3, pp. 493-530, 1989.

[42] Y.-R. Wang, C.-Y. Yu, and H.-H. Chan, "Predicting construction cost and schedule success using artificial neural networks ensemble and support vector machines classification models," Int. J. Proj. Manag., vol. 30, no. 4, pp. 470-478, 2012.

[43] D. K. H. Chua, P. K. Loh, Y. C. Kog, and E. J. Jaselskis, "Neural networks for construction project success," Expert Syst. Appl., vol. 13, no. 4, pp. 317-328, Nov. 1997.

[44] D. Dvir, A. Ben-David, A. Sadeh, and A. J. Shenhar, "Critical managerial factors affecting defense projects success: A comparison between neural network and regression analysis," Eng. Appl. Artif. Intell., vol. 19, no. 5, pp. 535-543, 2006.

[45] L. Rodriguez-Repiso, R. Setchi, and J. L. Salmeron, "Modelling IT projects success with Fuzzy Cognitive Maps,” Expert Syst. Appl., vol. 32, no. 2, pp. 543-559, Feb. 2007.

[46] F. Reyes, N. Cerpa, A. Candia-Véjar, and M. Bardeen, "The optimization of success probability for software projects using genetic algorithms," $J$. Syst. Softw., vol. 84, no. 5, pp. 775-785, May 2011.

[47] G. Thomas and W. Fernández, "Success in IT projects: A matter of definition?,” Int. J. Proj. Manag., vol. 26, no. 7, pp. 733-742, Oct. 2008.

[48] E. J. Jaselskis, “Achieving construction project success through predictive discrete choice models," University of Texas, Austin, 1988.

[49] K. Peffers, C. E. Gengler, and T. Tuunanen, "Extending Critical Success Factors Methodology to Facilitate Broadly Participative Information Systems Planning," J. Manag. Inf. Syst., vol. 20, no. 1, pp. 51-85, 2003.

[50] J. L. Salmeron and I. Herrero, "An AHP-based methodology to rank critical success factors of executive information systems," Comput. Stand. Interfaces, vol. 28, pp. 1-12, 2005.

[51] S. Abe, O. Mizuno, T. Kikuno, N. Kikuchi, and M. Hirayama, "Estimation of project success using Bayesian classifier," Proceeding 28th Int. Conf. Softw. Eng. - ICSE '06, no. 4, p. 600, 2006.

[52] C.-H. Ko and M.-Y. Cheng, "Dynamic Prediction of Project Success Using Artificial Intelligence," Journal of Construction Engineering and Management, vol. 133. pp. 316-324, 2007.

[53] Y.-R. Wang and G. Edward Gibson Jr., "A study of preproject planning and project success using ANNs and regression models," Autom. Constr., vol. 19, no. 3, pp. 341-346, 2010.

[54] M.-Y. Cheng, Y.-W. Wu, and C.-F. Wu, "Project success prediction using an evolutionary support vector machine inference model," Autom. Constr., vol. 19, no. 3, pp. 302-307, May 2010.

[55] J. S. Russell, E. J. Jaselskis, and S. P. Lawrence, "Continous assessment of project performance," J. Constr. Eng. Manag., vol. 123, no. 1, pp. 64-71, 1997.



Daniel Magaña Martínez obtained his degree as an Engineer in Computer Science, and MS in Project Management at the University Antonio de Nebrija, Madrid, Spain, in 2000 and 2012, respectively. Currently he is a lecturer in Project Management at the University Antonio de Nebrija, Madrid, Spain. His research interests include Early Warning Systems in Project management. Currently he is working as $\mathrm{CIO}$ at University Antonio de Nebrija,

Madrid, Spain.

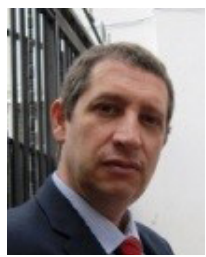

Dr. Juan Carlos Fernández-Rodríguez. $\mathrm{PhD}$ in Psychology (Universidad Complutense of Madrid ,Spain), Senior Technician in Risk Prevention and Diploma in Personnel Management. Currently he is Postgraduate Coordinator at University Antonio de Nebrija and Director of Prevention Programs. He has been involved in several research projects related to the Educational Technologies and Knowledge Economy and Globalization. He has published five books, several book chapters and various papers on matters of e-Learning and Educational Technology and Psychosocial maladjustment and its influence in education. 